explained on analytical grounds as lipid analyses performed in different laboratories give consistent results. ${ }^{3}$ Also, the men in the present study served as an internal control. The influence of diet and parity cannot be excluded as major contributors to this phenomenon, but Gupta and colleagues do not provide good data on these points. The endocrine control of plasma high density lipoprotein cholesterol concentrations has been widely studied, and the effect of insulin resistance in this group may be important. ${ }^{4}$

Gupta and colleagues' study adds weight to the increasing body of evidence that Asian women are at increased risk of coronary heart disease. We may expect an increase in the incidence of coronary heart disease in the British Asian population in the next decade, and further studies are urgently required.

NAVEED A SATTAR Registrar

ALLAN GAW

Lecturer

Royal Infirmary,

Glasgow G4 0SF

1 Gupta R, Gupta VP, Ahluwalia NS. Educational status, coronary heart disease, and coronary risk factor prevalence in a rural heart disease, and coronary risk factor prevalence in a rura

2 Heiss G, Tamir I, Davis CE, Tyroler HA, Rifkind BM

Schonfeld G, et al. Lipoprotein-cholesterol distributions in selected North American populations: the Lipid Research selected North American populations: the Lipid Research Clinics program prevalence study. Circulation 1980;61:302-15.
McKeigue PM, Marmot MG, Adelstein AM, Hunt SP, Shipley

3 McKeigue PM, Marmot MG, Adelstein AM, Hunt SP, Shipley MJ, Butler SM, et al. Diet and risk factors for coronary heart
disease in Asians in northwest London. Lancet 1985;ii: disease in Asians in northwest London. Lancet 1985;ii:
1086-90.

4 McKeigue PM, Shah B, Marmot MG. Relation of central obesity and insulin resistance with high diabetes prevalence and cardiovascular risk in South Asians. Lancet 1991;337:382-6.

\section{Temperature and cardiovascular mortality}

EDrToR,-As Peter Wilmshurst points out, international rates of cardiovascular disease generally become higher as the temperatures become colder'; this pattern holds true even within many countries. Scotland, however, shows the opposite, as colleagues and I found in our studies of geographical patterns of mortality from various diseases in Scotland. ${ }^{24}$ We examined the standardised mortality ratios for diseases during three quinquenniums (1959-63, 1969-73, and 1979-83) for the communities described in the annual reports of the registrar general for Scotland: 231 and 234 communities (cities, large and small burghs, and landward areas) in the first two quinquenniums respectively and the 56 local government districts in the last quinquennium.

The table shows the percentages of communities with standardised mortality ratios for coronary heart disease (International Classification of Diseases (ICD), seventh revision, codes 420-422; eighth and ninth revisions, codes 410-414) significantly
Department of Pathological Biochemistry,

$(P<0.05)$ high or low in the regions in the three categories of latitude (the corresponding numbers are given in the references). Because the diagnoses of coronary heart disease and cerebrovascular disease are liable to be confused, the pattern for heart disease would have been explicable as a diagnostic artefact if a reverse trend for cerebrovascular disease had been found. The comparable data for cerebrovascular disease (ICD, seventh revision, codes 450-468; eighth and ninth revisions, codes 430-438) showed a pattern broadly similar to that for heart disease, though less pronounced (table).

A knowledge of the locations of the regions or a view of the maps of these diseases ${ }^{2}$ also shows a tendency for mortality to rise from east to west. Thus the milder climate in the southwest and, indeed, along the whole west coast, due to the Gulf Stream seems also to promote higher mortality from cardiovascular diseases in the communitie there. By contrast, the colder and bleaker environment in the northeast seems to keep people's heart warm longer. What genetic (Celtish or Pictish) or dietary differences overrule the climatic gradien to cause this Scottish paradox?

OWEN LLLOYD

Faculty of Medicine and Health Sciences,

Department of Public Health and Ocupational Medicine, United Aab Emirates University,

United Arab Emirates

Wilmshurst $P$. Temperature and cardiovascular mortality. $B M F$ 1994;309:1029-30. (22 October.)

2 Lloyd OL, Williams FLR, Berry WG, Florey C du V, eds. $A$ atlas of mortality in Scotland. London: Croom Helm, 1987.

3 Williams FLR, Lloyd OL, Berry WG. High mortality from heart disease in SW Scottish communities during three quinquennia. Public Health 1986;100:343-51.

4 Williams FLR, Lloyd OL. Cerebrovascular disease in Scotland during 1959-1983: its geographical distribution and associations. Community Med 1989;11:306-15.

\section{Diagnosing pulmonary embolism}

EDITOR,-In his editorial on diagnosing pulmonary embolism Kenneth $\mathbf{M}$ Moser expresses the desire for a test-ideally rapid, non-invasive, and widely available - that "would rule in or rule out the diagnosis of venous thromboembolism with a high degree of certainty." A (nearly) exclusionary test would be valuable, especially when combined with other well studied non-invasive tests for deep vein thrombosis. Such a test exists and deserves wider recognition and use: liquid crystal thermography of the lower limbs. ${ }^{23} \mathrm{~A}$ normal result of this procedure excludes deep vein thrombosis with a high degree of certainty (97-100\%), ${ }^{24}$ and the test is rapid and non-invasive. It is not widely available, but there is no reason why it should not be. It is simple to perform, free of risk, and cheap in both capital and revenue costs.

Deep vein thrombosis is detected by liquid

Percentages of communities in three categories of latitude in Scotland with significantly high or low standardised mortality ratios (SMRs) for coronary heart disease and cerebrovascular disease

\begin{tabular}{|c|c|c|c|c|c|c|}
\hline \multirow[b]{2}{*}{ Region } & \multicolumn{3}{|c|}{ Significantly high SMR } & \multicolumn{3}{|c|}{ Significantly low SMR } \\
\hline & $1959-63$ & $1969-73$ & 1979-83 & $1959-63$ & $1969-73$ & $1979-83$ \\
\hline \multicolumn{7}{|c|}{ Coronary heart disease } \\
\hline $\begin{array}{l}\text { North (Highlands and Islands, } \\
\text { Grampian) }\end{array}$ & 0,3 & 12.3 & 18,0 & 28,17 & 28,23 & 0,80 \\
\hline Middle (Tayside, Central, Fife, & & & & & & \\
\hline $\begin{array}{l}\text { Lothian) } \\
\text { S }\end{array}$ & $10,7,8,5$ & $0,13,4,5$ & $0,33,66,0$ & $33,27,12,30$ & $24,13,15,25$ & $0,0,33,50$ \\
\hline $\begin{array}{l}\text { South (Strathclyde, Borders, } \\
\text { Dumfries and Galloway) }\end{array}$ & $43,24,16$ & $36,6,16$ & $63,0,75$ & $6,6,11$ & $11,18,0$ & $11,25,0$ \\
\hline \multicolumn{7}{|c|}{ Cerebrovascular disease } \\
\hline $\begin{array}{l}\text { North (Highlands and Islands, } \\
\text { Grampian) } \\
\text { Middle (Tayside, Central, Fife, }\end{array}$ & 8,17 & 24,6 & 27,20 & 28,26 & 28,29 & 9,60 \\
\hline Lothian) & $14,0,12,15$ & $10,13,8,25$ & $0,33,66,25$ & $24,0,31,10$ & $33,7,12,25$ & $33,0,33,50$ \\
\hline $\begin{array}{l}\text { South (Strathclyde, Borders, } \\
\text { Dumfries and Galloway) }\end{array}$ & $23,6,21$ & $29,12,42$ & $42,25,50$ & $11,12,11$ & $4,35,5$ & $21,25,25$ \\
\hline
\end{tabular}

crystal thermography because of increased skin temperature plus loss of the normal temperature gradient in the affected lower limb due to changes in the capillary skin circulation mediated by vasoactive amines released from the site of thrombus formation. The small percentage of false negative results is due to thrombi that are not propagating or undergoing thrombolysis; they are not likely to be a potential source of emboli and are therefore not of immediate clinical importance. A normal result of liquid crystal thermography thus effectively excludes deep vein thrombosis and saves the patient from unnecessary further investigation or treatment with anticoagulant drugs.

Liquid crystal thermography is non-specific, so confirmatory tests for deep vein thrombosis are indicated when the result is positive. Deep vein thrombosis can, however, be confidently excluded in over one third of patients in whom it is clinically suspected, and thus these patients can be spared further investigation. ${ }^{3}$ This results in considerable saving in time and effort with regard to conventional investigations and in revenue savings, no matter what method of investigation of deep vein thrombosis is usually used. In institutions where lower limb venography remains the usual investigation for deep vein thrombosis, use of liquid crystal thermography has the added advantage that the risks due to ionising radiation or allergy to contrast medium, which arise in $36 \%$ of patients, are avoided.

J RICHARD HARDING Consultant radiologist

Department of Clinical Radiology, Royal Gwent and St Woolos Hospitals,

Newport,

Gwent NP9 4SZ

1 Moser KM. Diagnosing pulmonary embolism. BMf 1994;309: 1525-6. (10 December.)

2 Sandler DA, Martin JF. Liquid crystal thermography as a screening test for deep-vein thrombosis. Lancet 1985;i:665-8.

3 Harding JR. Liquid crystal thermography in the investigation of suspected DVT. Br ₹ Radiol 1990;63:993-4.

4 Kalodiki E, Marston R, Volteas N, Leon M, Labropoulos N, Fisher CM, et al. The combination of liquid crystal thermography and duplex scanning in the diagnosis of deep vein thrombosis. Eur 9 Vasc Surg 1992;6:311-6.

5 Harding JR. Liquid crystal thermography in the investigation of deep venous thrombosis: a prospective study of 800 patients. Thermologie Osterreich 1994;4:183.

\section{Interpretation of electrocardiograms}

\section{Interpretation of the ECG is as much an art} as a science

EDrToR,-The ability to measure the PR and QT intervals accurately is useful for preclinical medical students. It might also reasonably be expected of cardiologists. It is not, however, equivalent to the intellectual process of interpretation of the electrocardiogram, as the title of Hugh Montgomery and colleagues' short paper suggests.' Interpretation often involves a doctor making a clinical diagnosis such as acute myocardial infarction, "old" myocardial infarction, left ventricular hypertrophy, or atrial fibrillation. The electrocardiogram is used extensively by the wide range of doctors who treat the commonest heart condition-that is, coronary artery disease. Accurate interpretation of the electrocardiogram in a patient with coronary artery disease is often difficult, and in many patients the abnormalities of the ST segment or $t$ wave can be described only as non-specific. Measurement of the PR or QT interval is rarely an important component of interpretation of the electrocardiogram in patients seen by general surgeons, cardiothoracic surgeons, or accident and emergency physicians.

Interpretation of the electrocardiogram is as much an art as a science. It is vital, for instance, for appropriate administration of thrombolytic treatment and deserves further investigation by more 
clinically relevant examples than the purely scientific questions posed by Montgomery and colleagues.

Royal London Hospital,

Consultant cardiologist

London E1 1BB

1 Montgomery $H$, Hunter $S$, Morris $S$, Naunton-Morgan $R$ Marshall RM. Interpretation of electrocardiograms by doctors. $B M \Im$ 1994;309:1551-2. (10 December.)

\section{Formal teaching can reduce serious errors} in interpretation

EDITOR,-We were not surprised by the results of Hugh Montgomery and colleagues' study of doctors' ability to interpret electrocardiograms. We have audited the ability of senior house officers to interpret electrocardiograms in an accident and emergency department. ${ }^{2}$ We found that only 114 of 245 traces were interpreted correctly but that management was seriously affected by misinterpretation in only eight cases. After forma teaching and the issue of guidelines serious errors of misinterpretation fell by half to four out of 242 ( $1.6 \%$; confidence interval $0.7 \%$ to $4 \%$ ).

We also tested the ability of cardiographers, cardiac technicians, nurses in the coronary care unit, anaesthetic registrars, and medical senior house officers to interpret electrocardiograms; we used a standard set of 20 electrocardiograms. All the subjects were asked to report the rate, rhythm, QRS axis, and abnormalities. Answers were graded 1-4, where 1=complete concordance; $2=$ minor disagreement (for example, first degree heart block); 3 =disagreement (for example, left ventricular hypertrophy); and $4=$ appreciable disagreement potentially affecting managemen (for example, ST segment elevation). All the paramedical staff were better than the doctors and made fewer serious errors (table; $\chi^{2}=27 \cdot 2$, $\mathrm{P}<0.01$ ).

We believe that these results are explained by the fact that formal training in interpretation of electrocardiograms is given to all the groups of staff that we tested except the doctors. It is an indictment of medical education that doctors can interpret electrocardiograms less well than paramedical staff. Should this interpretation be part of the undergraduate curriculum? We believe that it should certainly be part of postgraduate training for doctors in clinical specialties. It is particularly important when decisions about giving thrombolytic treatment to patients with acute myocardial infarction depend partly on interpretation of the electrocardiogram. If general practitioners begin to use thrombolysis in the community they must be capable of recording and interpreting an electrocardiogram.

PA WOODMANSEY Research registra

Medical studen

K S CHANNER

Consultant cardiologist

1 Montgomery H, Hunter S, Morris S, Naunton-Morgan R, Marshall RM. Interpretation of electrocardiograms by doctors. Marshall RM. Interpretation of electroc)

2 White T, Woodmansey PA, Ferguson DG, Channer KS

Improving the interpretation of electrocardiographs in an accident and emergency department. Postgrad Med $\mathcal{F}$ (in press).

Grade given to interpretation by different groups of staff of sample of 20 electrocardiograms (ECGs) *

\begin{tabular}{lccccc}
\hline Grade & $\begin{array}{c}\text { Registrar } \\
(\mathbf{n}=6)\end{array}$ & $\begin{array}{c}\text { Nurse in coronary care unit } \\
(\mathbf{n}=6)\end{array}$ & $\begin{array}{c}\text { Cardiac technician } \\
(\mathbf{n}=6)\end{array}$ & $\begin{array}{c}\text { Cardiographer } \\
(\mathbf{n}=5)\end{array}$ & $\begin{array}{c}\text { Senior house officer } \\
(\mathbf{n}=6)\end{array}$ \\
\hline 1 & 53 & 46 & 51 & 51 & 47 \\
2 & 13 & 19 & 8 & 6 & 10 \\
3 & 18 & 27 & 43 & 26 & 33 \\
4 & 36 & 21 & 23 & 17 & 30 \\
Total ECGs & 120 & 120 & 120 & 100 & 120 \\
\hline
\end{tabular}

*See text for details of grades.

\section{Continuous ambulatory electrocardiography in elderly people}

EDrTOR,-I J Räihä and colleagues' paper on the predictive value of continuous ambulatory electrocardiographic monitoring in elderly people digresses and therefore arrives at several misleading and clinically unsound recommendations. ${ }^{\prime}$ In a retrospective study the authors found several abnormalities on Holter monitoring that were associated with a high odds ratio for the risk of cardiac death over 10 years. The subjects had a mean age of about 75 .

The predictive value-as distinct from the odds ratio-is a statistical term indicating the likelihood that a patient in whom the result of a test is abnormal will have the disease in question (or, in this case, a poor outcome). With respect to the three factors found by Räihä and colleagues to be associated with a poor outcome, 95 patients had $>100$ ventricular ectopic beats during the day, of whom 32 died of cardiac causes over the next 10 years; 88 had multifocal ventricular ectopic beats at night, of whom 31 died of cardiac causes; and 79 had sinus pauses of $>1.5 \mathrm{~s}$ during the day, of whom 34 died of cardiac causes. Thus the predictive value that a given patient with one of the identified factors on Holter monitoring would die of heart disease over the ensuring 10 years was only slightly greater than 1 in 3 .

Even if we assume that these markers, which were defined arbitrarily and post hoc, are indeed valid, what possible benefit could there be in determining that a given 75 year old has a 1 in 3 chance of dying of heart disease during the next 10 years? To imply that Holter monitoring should be performed routinely to stratify the risk in elderly people and to recommend that "patients with these findings should be evaluated for silent ischaemic heart disease and sick sinus syndrome" seems the height of folly. The cardiological community generally accepts that giving antiarrhythmic drugs to patients with ventricular extrasystoles does more harm than good, and Räihä and colleagues themselves state that "the benefit of treating silent ischaemia in elderly patients is unclear." Adherence to the authors' clinical recommendations would not only be economically wasteful but also give rise to much unnecessary anxiety in a population already so concerned by its declining sense of wellbeing.

MAYER BASSAN

Jerusalem Heart Clinic of Kupat Holim Consultant cardiologist

Israel

1 Răihä IJ, Piha SJ, Puukka P, Sourander LB. Predictive value of continuous ambulatory electrocardiographic monitoring in elderly people. BMf 1994;309:1263-7. (12 November.)

\section{Weight in infancy and coronary heart disease in adult life}

EDrToR,-C H D Fall and colleagues' paper assumes that low weight at 1 year is a result of undernutrition and that greater weight is a result of better nutrition. ${ }^{1}$ Unfortunately, weight gain in the first year of life is not as straightforward as this.
When weight profiles of individual babies are examined in the early months considerable shifts across centile lines take place in both upward and downward directions as the baby leaves behind intrauterine influences on growth and grows under the direction of his or her own genetic machinery. ${ }^{2}$ In a study of weight gain over the first year in 66 normal term infants only $12 \%$ kept roughly in the same "centile channel" in which they were born; $28 \%$ showed downward crossing of centiles, while most showed upward crossing of centiles. ${ }^{3}$ The greatest shift occurred in the first three months.

Some babies of low weight at 1 year will therefore be those who were light at birth, for physiological or pathological reasons, and who maintain this phenotype. Some will have become small, having crossed various numbers of centile channels. These have not all necessarily failed to thrive but have simply recaptured their true growth phenotype. At the same time, there are those of higher weight who have continued a high weight profile at birth while others have reached this weight, having caught up from being relatively light at birth. It is therefore important to know more about the detailed patterns of growth in the babies in the authors' study who weighed $\leqslant 18 \mathrm{lb}$ $(\leqslant 8.2 \mathrm{~kg})$ and $\geqslant 26 \mathrm{lb}(\geqslant 11.8 \mathrm{~kg})^{\circ}$. Is metabolic disadvantage relevant to those whose weight continues in a low channel or in those whose weight has fallen from a higher centile and, if so, which type? Likewise, what of the protection conferred on those who are of higher weight at 1 year?

There is further confusion. In some of the earlier studies by the authors low birth weight was linked with later risks of high blood pressure and ischaemic heart disease. ${ }^{4}$ Yet a typical pattern of early weight gain in growth retarded neonates is to catch up-to reach a higher centile than they were at birth. ${ }^{2}$ This phenomenon is also found in some infants of appropriate weight for gestation. Some heavier children at 1 year will therefore probably be those who have caught up from intrauterine growth retardation. On the one hand, these are considered to be at risk of later cardiovascular disease, yet we now hear that they seem to be advantaged in being less vulnerable to later coronary artery disease.

It is an intriguing possibility that early growth may somehow be related to programming of later disease. But the literature on the subject contains contradictions that need to be explained.

D P DAVIES

University Department of Child Health,

University of Wales College of Medicine, Cardiff CF4 4XN

Professor of child health

1 Fall CHD, Vijayakumar M, Barker DJP, Osmond C, Duggleby $S$. Weight in infancy and prevalence of coronary heart disease in adult life. $B M F$ 1995;310:17-9. (7 January.)

2 Davies DP, Williams T. Is weaning babies in clinics worthwhile? $B M \mathcal{F} 1983 ; 286: 860-7$.

3 Davies DP, Martan R. Growth and growth charts. BMF 1980; 280:1188.

4 Barker DJP, Osmond C, Golding J, Kuh D, Wadsworth MEJ. Growth in utero, blood pressure in childhood and adult life and mortality from cardiovascular disease. $B M \mathcal{F}$ 1989;298:564-7.

\section{Simple aspiration for spontaneous pneumothorax}

EDrTor,-Editor's Choice in the issue of 19 November describes the clinical trial reported by John Harvey and Robin J Prescott-of simple aspiration versus intercostal drainage for spontaneous pneumothorax in patients with normal lungs'—as "methodologically strong." I challenge that view.

Firstly, patients "with signs of a tension pneumothorax" are said to have been excluded from the trial, presumably because intercostal tube drainage is considered to be mandatory in all such cases. But the criteria for that diagnosis are not stated, and at 